\title{
AJARAN MORAL DAN KARAKTER DALAM BUKU CERITA NUSANTARA SEBAGAI BAHAN AJAR SISWA SD
}

\author{
Aster Pujaning Ati ${ }^{1}$, Muthia Mubasyira ${ }^{2}$, \\ Loecita Sandiar ${ }^{3}$, Sigit Widiyarto ${ }^{4}$, Subhan Harie ${ }^{5}$ \\ 1,3,4Program Studi Pendidikan Ekonomi \\ ${ }^{2}$ Program Studi Pendidikan Bahasa Inggris \\ ${ }^{5}$ Program Studi Pendidikan Biologi \\ Universitas Indraprasta PGRI Jakarta \\ Jalan Nangka No.58 Tanjung Barat, Jakarta Selatan \\ Surel: asterpujaningati@ymail.com
}

\begin{abstract}
Abstrak
Pada saat siswa membaca sebuah buku cerita, tentunya ada banyak nilai - nilai yang terkandung dalam sebuah cerita. Pemahaman siswa dalam membca sangatlah menentukan untuk diambil ajaran dan karakter yang ada dalam buku tersebut. Data penelitian yang diambil adalah buku cerita nusantara sebanyak lima cerita rakyat nusantara. Metode dalam penelitian ini adalah metode kualitatif dengan pendektan menggunakan analisis deskriptif (menceritakan apa yang sudah dibaca). Dengan cara membaca buku-buku nusantara yang sedang diteliti, untuk mendapatkan hasil analisis mengenai cerita tersebut lalu dituangkan dalam bentuk tulisan. Teknik analisis data dengan pemilahan pesan dalam kalimat berdasarkan nilai pendidikan karakter yang ada dalam cerita. Hasil penelitian menunjukkan bahwa terdapat beberapa ajaran moral dan karakter pada teks buku cerita nusantara, diantaranya adalah, mau meminta maaf, kepasrahan, mau menerima takdir, mau mengkoreksi diri, bersyukur, sayang, berani, tegar, berprasangka baik dan bertutur kata halus.
\end{abstract}

Kata-Kata Kunci : Ajaran moral, karakter, cerita nusantara

\section{A. PENDAhULUAN}

Ajaran moral merupakan ajaran yang menjadi dasar untuk berbuat. Ajaran moral dapat terlihat pada sikap karakter yang dimiliki oleh siswa. Karakter siswa sangat beragam, bergantung pada pendidikan karakter yang diberikan kepada siswa, baik di rumah dan sekolah. Anak sebaiknya di didik sejak kanak-kanak sampai dewasa. Anak dituntun bersikap dewasa pada saat dia bergaul di lingkungan masyarakat. ajaran atau karakter anak harus mencerminkan karakter yang baik. Sikap anak dapat dipengaruhi oleh apa yang di abaca. Dengan membaca diharapkan siswa dapat mempunyai pandangan yang baik terhadap nilai atau ajaran karakter. Pada cerita biasanya dimaksudkan sebagai suatu saran atau ajaran moral yang bersifat praktis dan dapat diambil atau ditafsirkan lewat cerita (Kuratul, A.: 2019). Para orang tua kadang mengalami kesulitan dalam menanamkan ajaran karakter yang baik pada anak, sehingga anak tidak memahami dan cenderung tidak patuh atau bersikap kurang sopan kepada teman maupun kepada orang yang lebih tua. Penggunaan cerita nusantara, bermanfaat bagi pola pikir anak 
karena cerita anak nusantara dibaca oleh anak maupun dibacakan oleh orang tua, mampu diarahkan oleh orang tua dalam bersikap sebagaimana yang diperankan oleh tokoh dalam cerita nusantara tersebut. Cerita rakyat yang kaya akan nilai-nilai moral dan kearifan lokal, bisa dijadikan sebuah contoh yang baik (Maziyah, N., Rais, R., \& Kiswoyo, K. 2019). Anak juga tidak bersikap buruk serta mau mengikuti karakter tokoh cerita yang baik dalam suatu cerita.

Penelitian ini dilakukan karena peneliti melihat sikap siswa yang kurang baik terhadap guru dan orang tua mereka. Mereka perlu mendapat gambaran yang baik dengan membaca cerita-cerita nusantara yang sarat akan ajaran moral dan karakter. Dalam cerita tersebut terdapat nilai yang dapat diambil dalam kehidupan sehari-hari (Nurmala, S. (2020).

Penelitian terdahulu yang pernah dilakukan, berjudul analisis Nilai Spiritual dalam Pembentukan Karakter pada Buku Cerita Rakyat Karya Wirodarsono yang dilakukan oleh Maziyah.N, dkk pada tahun 2019, hasil penelitiaan menujukkan bahwa, buku cerita rakyat Joko Dolok mengandung 34 nilai spiritual yang dapat membentuk karakter siswa. Nilai-nilai spiritual dan nilai-nilai karakter tersebut dapat dilihat dari kutipan dalam penokohan, dan dibuktikan dari indikator iman, ibadah, dan akhlak serta indikator 18 nilai karakter, beberapa poin yang mempengaruhi nilai spiritual dalam buku cerita dapat membentuk nilai karakter yaitu dari lingkungan, banyaknya nilai spiritual yang ada didalam buku tersebut dan isi atau alur dari cerita tersebut. Dan tiga cara menanamkan nilai karakter pada siswa yaitu sebelum pembelajaran dimulai, saat pembelajaran dimulai dan saat diluar jam pembelajaran. Pada buku cerita tersebut banyak sekali ajaran moral dan karakter.

Demikian pula penelitian yang dilakukan oleh M Ridwan pada tahun 2016 yang berjudul Ajaran moral dan karakter dalam fabel kisah dari negeri dongeng karya Mulasih Tary. Hasil penelitian menunjukkan bahwa implementasi bahan ajar sastra anak di sekolah dasar akan menjadi bergairah apabila seorang guru mampu mendongeng tentang cerita binatang yang lucu-lucu atau melakukan monolog dengan penjiwaan yang maksimal di depan siswa. Melalui bahan ajar sastra anak, diyakini mempermudah mencapai proses dan tujuan pembelajaran yang diinginkan. Selanjutnya peneliti bertujuan untuk menganalisi ajaran moral dan karakter pada buku-buku nusantara. Manfaat penelitian ini untuk dapat memberikan pembelajaran karakter dari membaca buku-buku cerita nusantara yang sarat akan ajaran moral dan karakter pada siswa. 


\section{B. KAJIAN TEORI}

\section{Konsep Pembelajaran Ajaran Moral dan Karakter}

Secara etimologis, kata moral berasal dari kata mos dalam bahasa Latin, bentuk jamaknya mores, yang artinya adalah tata-cara atau adat-istiadat. Perilaku anak yang belum memasuki kriteria tata cara yang sudah disepakati dapat dikatakan belum bermoral. Pada situasi sekarang sering anak belum memahami tata cara atau adat istiadat dari para leluhur mereka. Hal ini dapat dimaklumi jika para orang tua belum memperkenalkan aturan tersebut, namun jika sudah diperkenalkan dan sudah diajarkan di rumah maupun di sekolah tetapi anak belum dapat menerapkannya dalam kehidupan sehari-hari tentunya perlu pengkajian ulang terhadap penerapan ajaran tersebut.

Selanjutnya karakter merupakan bentuk dan sifat yang ada dalam diri seseorang yang sudah terbentuk. Beberapa para ahli yang memberikan pengertian mengenai pendidikan karakter. Zubaedi (2012: 15) menyebutkan bahwa : Pendidikan karakter adalah usaha sengaja (sadar) untuk mewujudkan kebajikan, yaitu kualitas kemanusiaan yang baik secara objektif, bukan hanya baik untuk individu perseorangan tetapi juga baik untuk masyarakat secara keseluruhan. konsep pendidikan karakter yang dikemukakan dapat dipahami bahwa pendidikan karakter merupakan alternatif yang dapat ditempuh dalam pembentukan karakter individu. Pendidikan karakter yang diberikan kepada siswa, bergantung kepada contoh yang dilihat oleh siswa. Pendidikan karakter diusahkan dengan usaha yang tersusun dengan bai , agar individu yang terbentuk menjadi individu yang akan mampu melaukukan hala-ha yang baik. Individu yang terbentuk merupakan individu yang mampu mempertahankan nilai-nilai karakter sepanjang hayat, tidak tergoda oleh gangguan atau pengaruh dari luar. Berdasarkan kajian nilainilai agama, norma-norma sosial, peraturan/hukum, etika akademik, dan prinsip-prinsip HAM, telah teridentifikasi butir-butir nilai yang dikelompokkan menjadi nilai utama, adapun secara rinci nilai-nilai tersebut adalah:

1. Hubungannya dengan Tuhan, yaitu religius. Pikiran, perkataan, dan tindakan seseorang yang diupayakan selalu berdasarkan pada nilai-nilai Ketuhanan dan/atau ajaran agamanya.

2. Hubungannya dengan diri sendiri, yaitu jujur, bertanggung jawab, bergaya hidup sehat, disiplin, kerja keras, percaya diri, berjiwa wirausaha, berpikir logis, kritis, kreatif, dan inovatif, mandiri, ingin tahu, cinta ilmu 
3. Hubungannya dengan sesama, yaitu sadar akan hak dan kewajiban diri dan orang lain, patuh pada aturan-aturan sosial, menghargai karya dan prestasi orang lain, santun, demokratis.

4. Hubungan dengan lingkungan, yaitu peduli akan sosial dan lingkungan ditunjukkan dengan sikap dan tindakan selalu berupaya mencegah kerusakan pada lingkungan alam sekitarnya, dan mengembangkan upaya-upaya untuk memperbaiki kerusakan alam yang sudah terjadi dan selalu ingin memberi bantuan bagi orang lain dan masyarakat yang membutuhkan.

5. Nilai kebangsaan, yaitu nasionalis dan menghargai keberagaman.

\section{Pola Ajar dan Pengasuhan Karakter pada Anak}

Pembicaraan mengenai pola pengasuhan anak merupakan hal baru bagi masyarakat Indonesia. Generasi sebelumnya lebih banyak mengasuh anak berdasarkan kebiasaan secara turun temurun. Di masa lalu, pengasuhan identik dengan pemenuhan sandang, pangan, papan, kesehatan dan pendidikan yang memadai. Namun dunia berubah, pemenuhan kebutuhan pokok anak saja sudah tidak cukup karena sekarang beragam tawaran nilai kehidupan menerpa dari berbagai arah. Belum lagi ada tuntutan bagi orang tua untuk tidak mengabaikan kesejahteraan dan kebahagiaan anak. Oleh sebab itu, orang tua perlu memikirkan cara terbaik mengasuh anak. Mencari pola terbaik masa kanak-kanak, yang dibatasi pada rentang usia 0-18 tahun, seringkali dianggap masa persiapan memasuki kehidupan orang dewasa yang penuh tanggung jawab dan berkontribusi positif bagi lingkungannya. Selama proses itu berlangsung, mereka perlu belajar beberapa hal penting sesuai dengan usianya.

Pada rentang usia tersebut, anak mengalami masa pertumbuhan fisik dan mental yang pesat. Karena pertumbuhan fisik dan mental yang pesat, maka dibuat beberapa pengelompokan dengan rentang usia yang lebih pendek: bayi, kanak-kanak, remaja dan dewasa muda. Pengelompokan usia ini akan membantu orang tua untuk mampu lebih teliti menerapkan pola pengasuhan digital yang berbeda pada masing-masing rentang umur itu. Pembagian kelompok usia ini juga menjadi panduan bagi orang tua untuk dapat memberi rangsangan, aturan, fasilitas dan pendampingan yang tepat sesuai tahap pefiumbuhan.

Dengan demikian anak mampu mengoptimalkan potensi mereka dan terhindar dari ancaman.Tantangan untuk memaksimalkan potensi anak semakin berat saat kita memasuki era digital. Era digital menawarkan beragam kesempatan baru untuk 
mengembangkan diri, namun juga menyimpan ancaman. Oleh karena itu, penting bagi orang tua mengembangkan model pengasuhan yang bertujuan menghindarkan anak dari ancaman dan memaksimalkan potensi digital. Teknologi digital membawa beberapa perubahan penting dalam kehidupan manusia, maka orang tua perlu memahami bentukbentuk perubahan itu agar dapat memandu anaknya. Pengasuhan digital menawarkan beberapa nilai dasar yang dapat diterapkan di dalam keluarga.

Secara umum ada tiga bentuk pengasuhan yang dilakukan orang tua di seluruh dunia: otoriter, otoritatif, permisif. Selain ketiga cara itu, ada juga keluarga yang menggunakan pendekatan agama atau budaya dalam mendidik anak. Masing- masing pilihan ditentukan orang tua berdasarkan pandangan mereka terhadap nilai-nilai kehidupan dan tantangan jaman. Apapun bentuk pengasuhannya, hal terpenting adalah orang tua konsisten dalam menjalankannya.

\section{METODE PENELITIAN}

Penelitian ini dilakukan dengan menggunakan deskriptif kualitatif. Metode ini merupakan tahapan penelitian untuk menganalisis dan menyajikan kenyataan berupa data dimensi ajaran moral dari cerita nusantara yang berjumlah lima buku, adapaun judul buku cerita nusanatara meliputi, 1) Si cantik dan sang pemberani ,cerita rakyat dari Kalimantan tengah, 2) Raja Madura yang perkasa dan bijaksana, cerita dari jawa-timur ), 3) Asal mula air asin di Telaga Yenauwyau dan 4) Jaka dan naga sakti cerita dari Jawa-timur, untuk dideskripsikan dengan menggunakan interpretasi yang sifatnya kualitatif. Penelitian ini menggunakan metode deskriptif kualitatif, yaitu suatu metode yang berusaha menggambarkan secara sistematis, fakta-fakta dan ciri-ciri data berupa ajaran moral yang dianalisis, dengan menggunakan pendekatan deskriptif-analitik. Penggunaan metode deskriptif dan beberapa pendekatan ini karena dipandang sesuai dengan masalah dan tujuan penelitian yang telah ditentukan serta berusaha mendeskripsikan sejumlah kegelisahan masyarakat tentang krisisnya moral anakanak usia sekolah dasar dan perlunya implementasi ajaran moral yang dihasilkan dari kajian ke empat buku cerita nusanatara tersebut. Penelitian ini memakai 3 tahap, yaitu mulai dari pengumpulan data, analisis data, dan penyimpulan. 


\section{HASIL DAN PEMBAHASAN}

Pada hasil penelitian akan dipaparkan beberapa cuplikan bacaan yang mengandung ajaran moral dan karakter. Hal ini perlu disajikan agar analisis buku nusantara yang banyak akan nilai ajaran moral dan karakter dapat diperhatikan bagi siswa dan para pendidik serta orang tua. Ada banyak hal cerita yang mengandung ajaran yang bermanfaat bagi metode pembelajaran siswa. Pada hasil analisis, penulis melihat ada beberapa karakter dan ajaran moral yang sangat patut, menjadi tuntunan moral siswa pada saat ini, nanyak karakter anak yang menyimpang, seperti mudah tersinggung dan marah.

\section{Tabel 1 Deskripsi Ajaran Moral dan Karakter}

\begin{tabular}{|c|c|c|c|}
\hline No & Judul & Deskripsi & Nilai yang terkandung \\
\hline \multirow[t]{4}{*}{1} & $\begin{array}{l}\text { Si cantik dan sang } \\
\text { pemberani }\end{array}$ & $\begin{array}{l}\text { "Ayah, Ibu aku minta maaf, aku tadi } \\
\text { mau minta maaf. } \\
\text { Hanya ingin keluar sebentar",bisik } \\
\text { Pongota. }\end{array}$ & mau minta maaf \\
\hline & & $\begin{array}{l}\text { "maafkan aku burung enggang. } \\
\text { Keluargaku menanti daging lezatmu" }\end{array}$ & mau minta maaf \\
\hline & & $\begin{array}{l}\text { "Pemuda pongandian yang ini sangat } \\
\text { pemberani" }\end{array}$ & sifat berani \\
\hline & & "Ah tidak mungkin ia seorang hantu". & prasangka baik \\
\hline \multirow[t]{4}{*}{2} & $\begin{array}{lr}\text { Raja Madura yang } \\
\text { Perkasa } & \text { dan } \\
\text { Bijaksana } & \end{array}$ & $\begin{array}{l}\text { "Lakukanlah demi kebaikan rakyat." } \\
\text { "Ayah sangat sayang.", jawab raja } \\
\text { lembut. }\end{array}$ & budi tutur kata halus \\
\hline & & $\begin{array}{l}\text { "Jagalah kesehatan aku selalu men } \\
\text { yayangi kalian,sahut putri dengan } \\
\text { tegar." }\end{array}$ & sifat tegar \\
\hline & & $\begin{array}{l}\text { Tanpa rasa takut mereka mendekati } \\
\text { Pulau Madu itu. }\end{array}$ & sifat berani \\
\hline & & $\begin{array}{l}\text { "Aku akan menjaga dan merawat Nyai, } \\
\text { seperti ibu kandungku sendiri." }\end{array}$ & sifat sayang \\
\hline 3 & $\begin{array}{l}\text { Asal mula air asin di } \\
\text { telaga Yenauwyau }\end{array}$ & $\begin{array}{l}\text { Maka sudah sepantasnya dan layak } \\
\text { untuk bersyukur. }\end{array}$ & sifat bersyukur \\
\hline
\end{tabular}




\begin{tabular}{l|l|l|l}
\hline & & $\begin{array}{l}\text { "Maafkan Gora, Bapak.", memelas } \\
\text { minta maaf kepada bapaknya }\end{array}$ & mau meminta maaf \\
\hline & $\begin{array}{l}\text { Mereka tidak memperdebatkan siapa } \\
\text { yang salah. }\end{array}$ & mau mengoreksi diri \\
\hline 4 & Jaka dan Naga Sakti & $\begin{array}{l}\text { Ia mengagumi kepasrahan yang } \\
\text { ditunjukkan oleh pemuda itu. }\end{array}$ & kepasrahan \\
\hline & $\begin{array}{l}\text { Berusaha menerima kenyataan, Jaka } \\
\text { Badu tidak berhasil. }\end{array}$ & mau menerima takdir \\
\hline & "Maafkan kelancangan hamba". & mau meminta maaf
\end{tabular}

Pada tabel di atas dapat dilihat beberapa ajaran moral pada teks buku cerita nusantara, diantaranya adalah, mau meminta maaf sebanyak, kepasrahan, mau menerima takdir, mau mengkoreksi diri, bersyukur, sayang berani, tegar, berprasangka baik dan bertutur kata halus. Nilai-nilai tersebut merupakan ajaran moral, yakni nilai yang mempersoalkan mana yang baik dan mana yang buruk (Purwaningsih, 2010). Nilai moral diklasifikasikan menjadi nilai moral individual, nilai sosial dan nilai religious (Sulistyorini, 2003) salah satunya mau minta maaf, pada saat ini para siswa kurang terampil untuk mau meminta maaf, bahkan membela diri demi kesalahan yang sudah dikerjakan. Mau meneriman takdir dan kepasrahan juga masih relevan pada pendidikan karakter saat ini hal termasuk hubungan manusia dengan Tuhannya (Nugiyantoro, 2000), karena siswa tidak pasrah menerima kenyataan yang ada, siswa cenderung mengeluh dan menyalahkan. Mengkoreksi diri lebih baik ketimbang menyalahkan orang, siswa dapat memetik dari cerita ajaran moral ini. Bersyukur ,sayang dan tegar merupakan karakter yang diperlukan pada zaman era digital, siswa dapat menghadapai tantangan zaman. Berprasangka baik dan bertutur kata halus merupakan luaran yang dapat terlihat dari ciri karakter siswa sehingga siswa dapat memberikan perilaku yang sopan dan dinamis.

Dari hasil analisis tersebut dapat disimpulkan bahwa cerita rakyat nusantara tersebut dapat dijadikan sebagai bahan ajar di Sekolah Dasar untuk meningkatkan penerapan moral dan karakter peserta didik. Penerapan dalam kegiatan proses pembelajaran akan memudahkan pemahaman peserta didik dalam menerapkan nilai moral dan karater. 


\section{E. KESIMPULAN}

Pada analisis buku cerita nusantara terdapat ajaran moral pada teks buku cerita nusantara, diantaranya adalah, mau meminta maaf, kepasrahan, mau menerima takdir, mau mengkoreksi diri, bersyukur, sayang berani, tegar, berprasangka baik dan bertutur kata halus. Dapat disimpulkan bahwa 1) buku cerita nusantara merupakan cerita ajaran moral dan karakter yang sudah diajarkan turun menurun seak dahulu kala,2) buku cerita tersebut sangat cocok sebagai buku ajar moral dan karakter siswa Sekolah dasar, karena bahasa yang mudah dipahami serta dapat diambil hikmah dari cerita tersebut.

\section{F. SARAN}

Para guru dan orang tua murid dapat membiasakan siswa untuk gemar membaca buku-buku yang berkarakter, agar dapat memahami ajaran moral dan karakter yang baik. Untuk meningkatkan kajian ilmu, khususnya pada bidang pendidikan moral dan karakter, pada penelitian selanjutnya sebagai pertimbangan peneliti menyarankan untuk dapat menggali ajaran moral dan karakter pada buku-buku cerita daerah. Buku tersebut kaya akan nilai-nilai identitas daerah.

\section{DAFTAR PUSTAKA}

Ati, A. P., \& Widiyarto, S. Literasi Bahasa Dalam Meningkatkan Minat Baca dan Menulis Pada Siswa Smp Kota Bekasi. Basastra, 9(1), 105-113.

Hadi, S., Puspita, F., Ati, A. P., \& Widiyarto, S. (2020). Penyuluhan dan pembelajaran karakter melalui pelaksanaan idul adha pada siswa SMA. Jurnal Pemberdayaan: Publikasi Hasil Pengabdian Kepada Masyarakat, 4(2), 205-210.

Herlina d.S,Setiawan B,Adikara,G.J (2018) Digital Parenting:Mendidik anak di era digital, Yogyakarta : Samudra Biru

Kuratul, A. (2019). Analisis Nilai-Nilai Moral Dalam Cerita Anak Pada Buku Siswa Kelas V Untuk Sekolah Dasar (Doctoral Dissertation, Stkip Pgri Sumenep).

Maziyah, N., Rais, R., \& Kiswoyo, K. (2019). Analisis Nilai Spiritual dalam Pembentukan Karakter pada Buku Cerita Rakyat Karya Wirodarsono. Indonesian Values and Character Education Journal, 2(1), 11-18.

Nurmala, S. (2020). Nilai Moral Cerita Rakyat Dalam Buku Cerita Daerah Sulawesi Tenggara. Jurnal Bastra (Bahasa Dan Sastra), 5(1), 45-56. 
Nurgiyantoro, Burhan. 2013. Sastra Anak; Pengantar Pemahaman Dunia Anak. Yogyakarta: Gadjah Mada University Press.

Nugiyantoro, B (2010). Teori Pengkajian Fiksi. Yogyakarta: Gadjah Mada University.

Re-trieved fro

Purwaningsih, E. (2010). Keluarga dalam Mewujudkan Pendidikan Nilai sebagai UpayaMengatasi Degradasi Moral. Jurnal Pendidikan, Sosiologi, Dan Humaniora, 1(1), 43-56

Rosadi, N., \& Widiyarto, S. (2020). Character Development for Class IX Studentsthrough Critical Reading Activities at MTs Nurul Hikmah and Driewanti Middle School Bekasi, West Java. KANGMAS: Karya Ilmiah Pengabdian Masyarakat, 1(1), 812.

Widiyarto, S., \& Sartono, L. N. (2020). Analisis nilai pendidikan karakter dan moral filmkoala kumal. Pena Kreatif: Jurnal Pendidikan, 9(2), 50-53.

Wulansari, L., Cleopara, M., Sahrazad, S., Sartono, L. N., \& Widiyarto, S. (2020).Penyuluhan Pendidikan Karakter Kepada Para Guru Smp Kota Bekasi. Community Development Journal: Jurnal Pengabdian Masyarakat, 1(3), 447451. 